\title{
Optimal Locations of Groundwater Extractions in Coastal Aquifers
}

\author{
Júlio F. Ferreira da Silva • Naim Haie
}

Received: 9 June 2004 / Accepted: 17 July 2006

(C) Springer Science + Business Media, B.V. 2006

\begin{abstract}
A regional water supply management model for coastal aquifers was developed. One of its outcomes is the definition of the optimized locations for groundwater withdrawal. Such a tool permits the analysis of alternative plans for groundwater extraction and the sustainable use of water resources in a coastal aquifer subject to saltwater intrusion. The principal components are the evolutionary optimization and the analytical/numerical simulation models. The optimization technique looks for the best well locations taking into consideration the economic results and the satisfaction of the societal water demand. However these two concerns are conditioned by trying to control the saltwater intrusion, i.e., preserving the environmental equilibrium. The simulation model uses the governing mathematical equations for groundwater movement to find the interface between freshwater and saltwater. Because of the non-linearity in the system and the possibility of a jumping interface, a security distance was defined. This is a controlling variable which can be set by the decision makers. The model was applied to a typical case with interesting results. For example, diagrams showing the relationship between the location of the wells and the security distance(s) are of importance to the managers. It was also crucial to have an understanding of the tradeoffs between groundwater withdrawals, positions of the wells from the coast line, and the security distance. The model was also applied to a real case in order to relate the extractions, distances and artificial recharge (not presented in this paper).
\end{abstract}

Key words well location · security distance for wells $\cdot$ saltwater intrusion ·

coastal groundwater extraction $\cdot$ water supply management

\section{Symbols}

as, ab, cs, cb, $\alpha, \beta \quad$ Coefficients of the cost and benefit functions

$B \quad$ Benefit (Euro)

$b \quad$ Subscript, surface and/or imported water, goes from 1 to $N_{b}$

C Cost (Euro)

$\mathrm{CIC}_{s} \quad$ Cost of investment in the groundwater withdrawal for $s$ (Euro)

J. F. Ferreira da Silva $\cdot$ N. Haie $(\square)$

School of Engineering, University of Minho, Campus of Azurém, 4800-058 Guimaraes, Portugal

e-mail: naim@civil.uminho.pt 


$\begin{array}{ll}D & \text { Water demand }\left(\mathrm{m}^{3} / \mathrm{s}\right) \\ \mathrm{ds} & \text { Security distance }(\mathrm{m}) \\ e & \text { A factor related to the commercial strategy of the constructor } \\ & \text { or installer and the market situation } \\ f & \text { Subscript, goes from } 1 \text { to } N_{f} \\ H & \text { Elevation height }(\mathrm{m}) \\ h & \text { Piesometric head (m) } \\ h_{0} & \text { (h zero), minimum allowable peisometric head (m) } \\ I & \text { Index, } I=N_{s}+N_{b} \\ N_{b} & \text { Number of surface and/or imported water points or entities } \\ N_{\mathrm{cp}} & \text { Number of control points such as wells } \\ N_{f} & \text { Number of the phases in the construction work and equipment } \\ N_{s} & \text { installation } \\ \mathrm{PS} & \text { Number of groundwater extraction points } \\ Q & \text { Pumping station } \\ Q_{1} & \left.\text { Flow rate, extraction, withdrawal (m }{ }^{3} / \mathrm{s}\right) \\ r & \text { (Q one), the first } Q \\ \mathrm{RDR} & \text { Subscript, for rehabilitation of aquifers such as recharge } \\ \text { RPR } & \text { Reservoir for distribution regulation } \\ s & \text { Reservoir for pumping regulation } \\ t & \text { Subscript, goes from } 1 \text { to } N_{s} \\ v_{t} & \text { time (year) } \\ \text { WTP } & \text { A factor that transforms a future value to a present one } \\ X_{\mathrm{cp}} & \text { Water treatment plant } \\ X_{s} & \text { Distance of the control point from the coast (m) } \\ X_{\mathrm{toe}} & \text { Distance of each well from the coast }(\mathrm{m}) \\ Y_{s} & \text { Distance of the toe of the interface from the coast (m) } \\ Z & \text { Distance along the coast (m) } \\ & \text { Objective function (Euro) } \\ & \end{array}$

\section{Introduction}

Water is more and more a precious resource to be managed with care and concern. Because of climate change and socio-economic transformations, attentions are increasingly towards a proper utilization of water. Predictions are indicating that in many parts of the world water stress is increasing. If you are in a coastal area, there are more difficulties involved because of the possibilities of the advance of seawater into the aquifers and estuaries.

The management of the water supply systems that use groundwater from aquifers prone to saline water contamination is a complex task. Such management models at varying degrees of success have been reported in the literature (Shamir et al. 1984; Essaid 1990; Finney and Willis 1992; Emch 1995; Hallaji and Yazicigil 1996; Nashikava 1998; Benhachmi et al. 2003).

At the European Union, quantitative and qualitative Groundwater Status of the water policy-the so-called Water Framework Directive-sets forth the managing criteria of saltwater intrusion (WFD 2000). In general and as related to this paper, the extraction of groundwater resources at the coastal aquifers poses a number of questions. For example, there is an interest in the number of viable locations for wells, each having a specific flow 


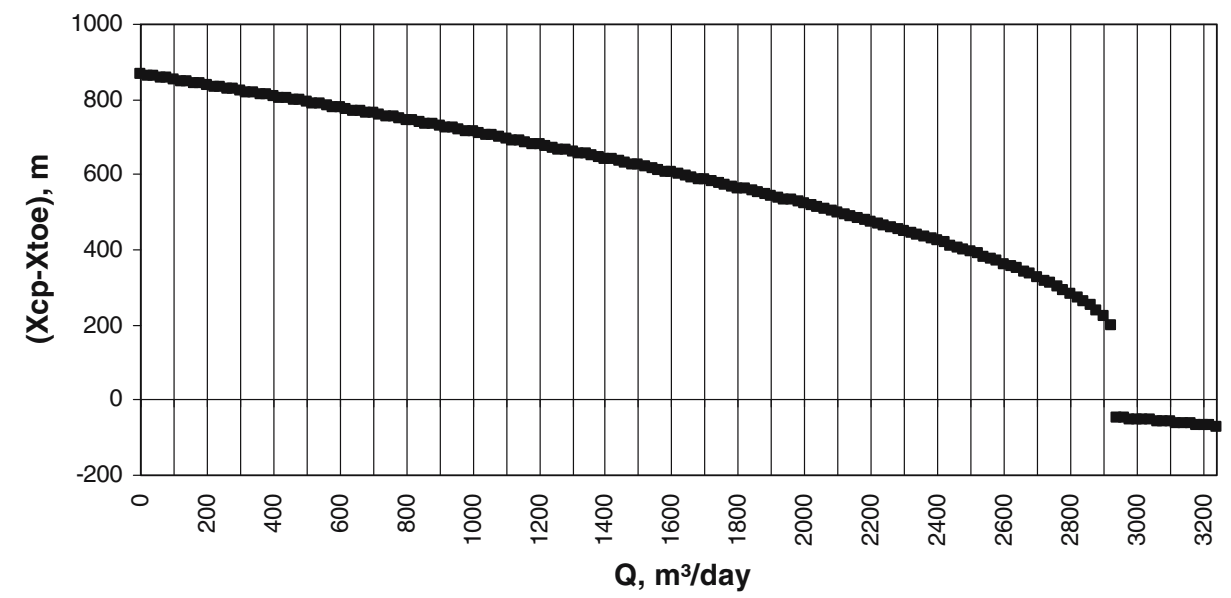

Figure 1 The distance between the control point and the toe of the interface vs. groundwater extraction (the jump of the toe).

Figure 2 A general scheme for a groundwater withdrawal and water supply system in a coastal region (river can be used for artificial recharge).

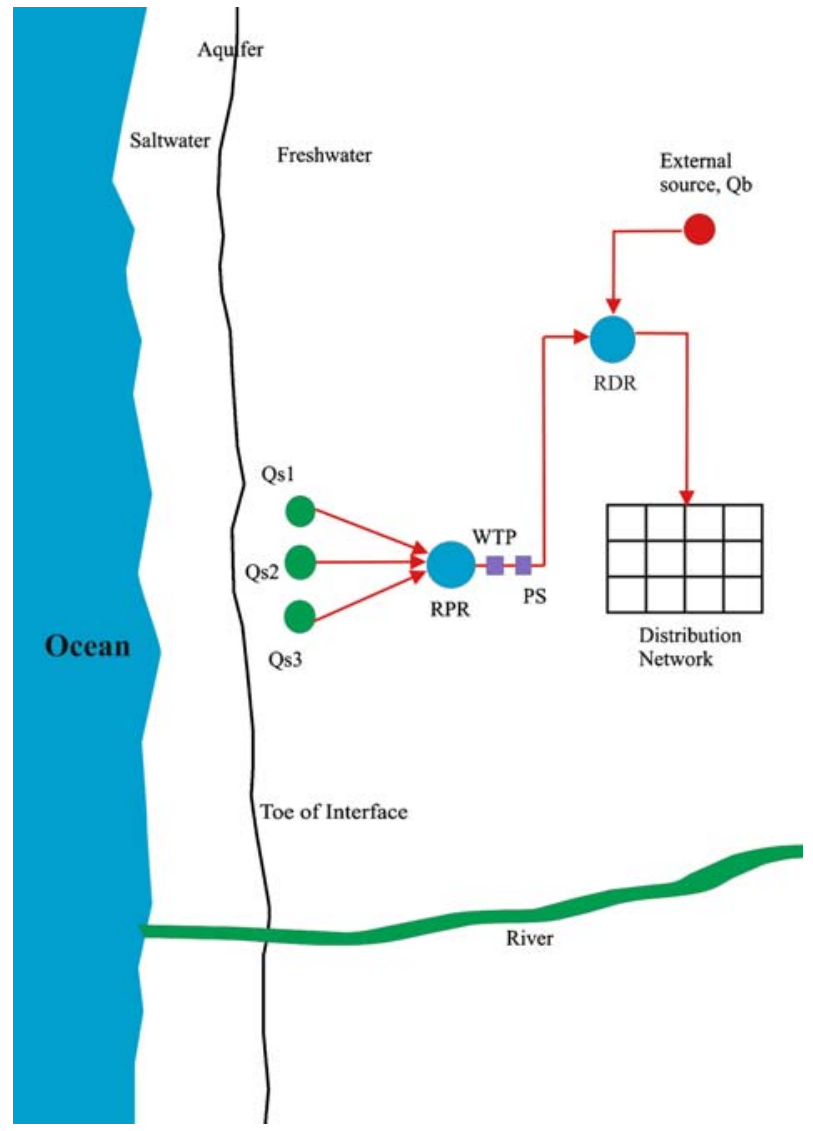


rate, in order to satisfy the demand (social dimension), maximizing the economic benefits (economical aspects) and controlling the saltwater intrusion (environmental concern).

Because of the accelerated changes mentioned above, the lower costs of groundwater usage, and the local availability of this resource, there is a great interest in capturing as much of the groundwater that flows into the sea as possible. Hence there is a growing need for management tools that position wells and define withdrawals in a sustainable manner. Proper artificial recharge and its locations are other aspects of the same issue. In all these situations, the non-linearity within the system has to be taken into account. Trying to extract the maximum quantity before experiencing saltwater intrusion is very risky, as can be seen in Figure 1.

\section{Methodology}

The solution to the problem of optimized implementation and management of extractions from aquifers potentially subject to saltwater intrusion consists in determining the best well location with a specific flow rate. This will give rise to the amount of water to be solicited from a surface water body and/or an external supplier (eventually a regional main water supply system). Naturally all of the water 'produced' should satisfy the total user demand without causing saltwater intrusion. Such a management scheme asks for the combined use of optimization and simulation techniques of the physical processes. Different types of aquifers result in different flow mechanisms needing their proper modeling. In the context of this paper, a Darcian type aquifer was simulated (Strack 1989; Benhachmi et al. 2003) with hydraulic characteristics given in the following Application section.

Evolutionary optimization methods have been used successfully in a variety of cases. Goldberg (1989) explains general structures of Genetic Algorithms and shows their relative simplicity. Simulated Annealing (Rao et al. 2003) has proved to be more promising in some cases. In groundwater optimization systems, Benhachmi et al. (2003) have also been successful using such methods. The simulation models like those by Strack (1989) and Bakker and Schars (2002) anticipate the behavior of the aquifer and the components of the

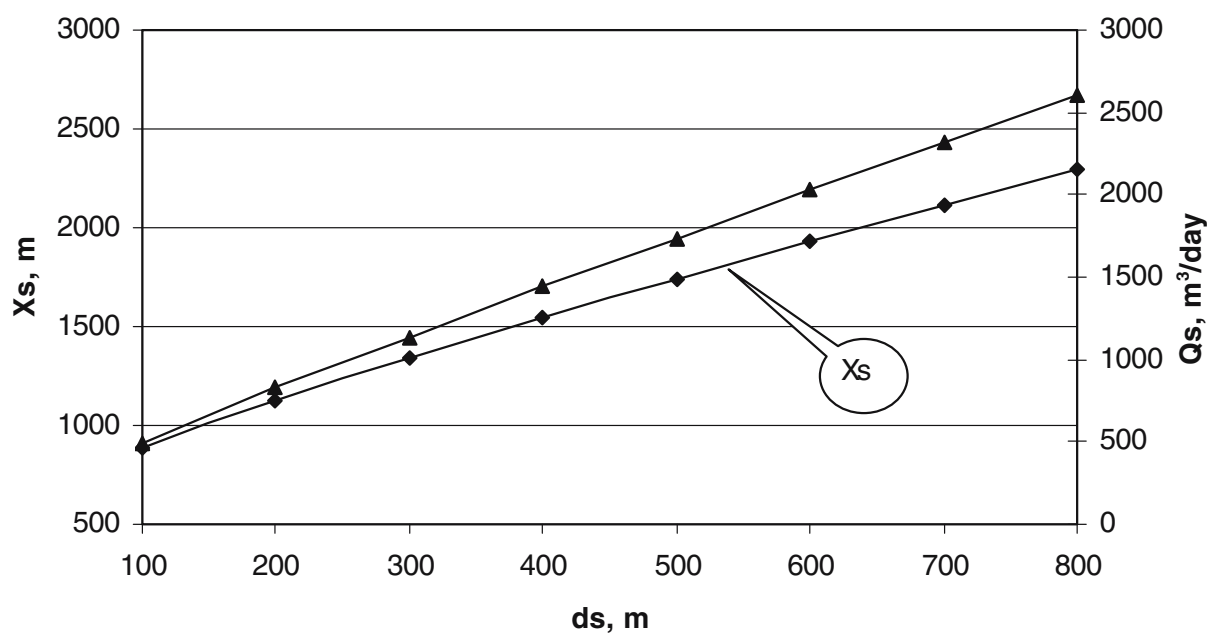

Figure 3 Security distance $(d s)$ vs. location $\left(X_{s}\right)$ vs. maximum withdrawal $\left(Q_{s}\right)$ for one well. 
water transport system in relation to the alternatives generated by the optimization tools. Ferreira da Silva (2003) defends a methodology that associates optimization (evolutionary) and simulation of coastal intrusion in a cascade of increasing degree of complexity (Ferreia da Silva and Haie 2004). The assumed sharp interface between freshwater and saltwater is proved to be conservative (Essaid 1990), i.e., the solutions of the groundwater management system are on the secure side.

In a regional conception and dimensioning of the groundwater extraction and water supply systems, there are various components that introduce investment and operational costs depending on the location and the quantity of the groundwater withdrawals. Extraction points condition the length of the main water supply system that transports groundwater to the treatment station. The maximum values for withdrawals determine the diameters of the mains, the capacity of the reservoir for pumping regulation, the selection of water treatment equipments, the selection of electro-mechanic equipments for the pumping station, the piping system downstream from the treatment plant, and the capacity of the reservoir for distribution regulation (Figure 2).

\section{Problem Formulation}

The management model defines the location and the rules for the extraction and the recharge that satisfies the demand, respects the restrictions, takes into consideration the economic aspects, and maintains saltwater at distance. In other words, the problem is to maximize the economic return while controlling the saltwater intrusion. This objective is mathematically represented by maximizing the difference between the total benefits $(B)$ and costs $(C)$ in a region during the analysis period (all the symbols are defined at the end of this paper):

$$
\max Z=\left(B_{\text {total }}-C_{\text {total }}\right)
$$

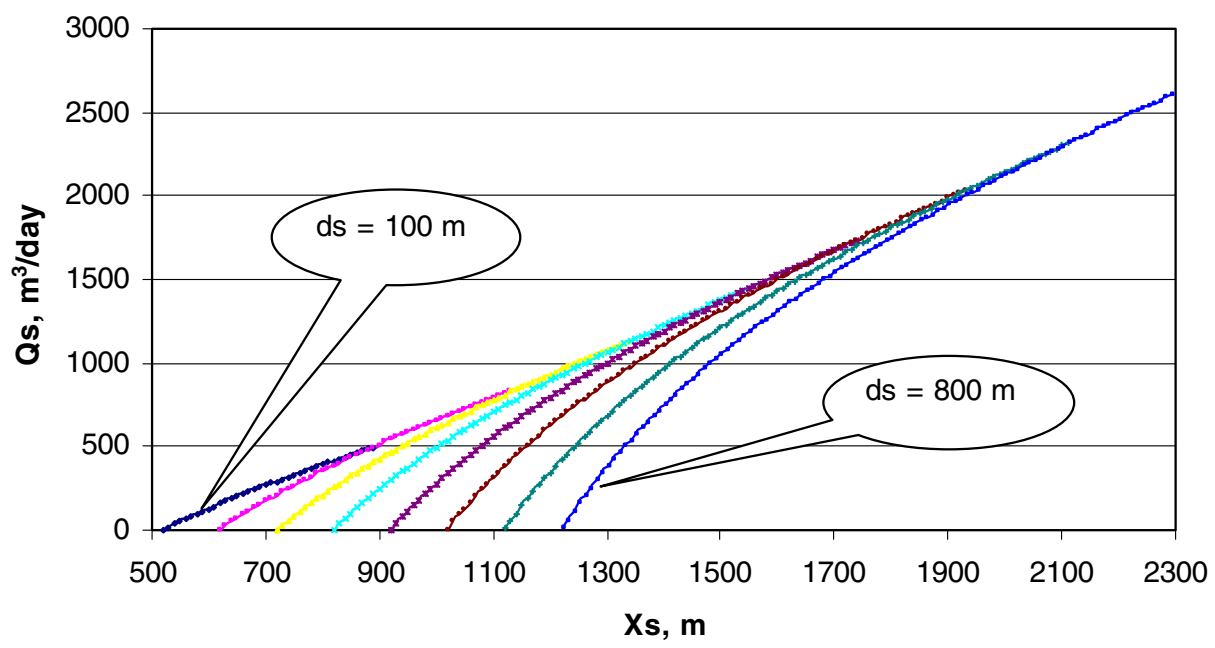

Figure 4 Extraction as a function of the security distance and location for one well (ds $=100,200, \ldots$, $800 \mathrm{~m}$ ). 
The global benefit can be calculated using the flows for different sources of water:

$$
B_{\text {total }}=\sum_{s=1}^{N_{s}}\left(c_{s}+a_{s} Q_{s}^{\beta_{s}}\right)+\sum_{b=1}^{N_{b}}\left(c_{b}+a_{b} Q_{b}^{\beta_{b}}\right) .
$$

The total cost of the project is based on the expenditures associated with the groundwater withdrawals, the surface and/or imported water, and the systems linked to degradation prevention and environmental rehabilitation (like artificial recharge):

$$
C_{\text {total }}=\sum_{t}^{T}\left(C_{s, t}+C_{b, t}+C_{r, t}\right) .
$$

The existence of each component of the water supply system and/or artificial recharge (wells, pumping stations, treatment plants, pipes, reservoirs) implies costs with the construction work and the equipment installation. These investments can be expressed by tables or aggregate models of the type:

$$
\mathrm{CIC}_{s}=\sum_{f=1}^{N_{f}} v_{t}\left(c_{s}+a_{s} H_{s, f}^{\alpha_{s}} Q_{s, f}^{\beta_{s}}\right) e \quad s=1,2,3, \ldots, N_{s} .
$$

The operating costs during the life of the project and according to the source of the water depend on the flow regime, length of the pipes, elevation height, and a number of other parameters. The complete characterization and quantification of the costs and benefits involved in the management of coastal systems can be found in Ferreira da Silva (2003).

To elaborate mathematically the restrictions on the system, the notion of the distance between the toe of the interface (between freshwater and saltwater) and one or more control points was introduced. These could be the wells that condition the solutions and their eventual locations near the ocean. If a number of extraction points are intended to be implemented, generally the control points should be defined as those that are more centrally located. In order to protect the control points from the invasion of saltwater, the following expression was defined:

$$
5\left(X_{\mathrm{toe}}\right)_{s} \leq\left(X_{\mathrm{cp}}\right)_{s}-(\mathrm{ds})_{s} \quad \forall s, s=1,2,3, \ldots, N_{\mathrm{cp}}
$$

Besides this constraint on the advance of the toe of the interface, it is also necessary to define other restrictions such as related to the satisfaction of the total demand, limits of each well withdrawal, and minimum piezometric heads:

$$
\begin{gathered}
\sum Q_{i}=D \quad \mathrm{i}=1,2,3, \ldots,\left(N_{s}+N_{b}\right) \\
Q_{i, \min } \leq Q_{i} \leq Q_{i, \max } \quad i=1,2,3, \ldots,\left(N_{s}+N_{b}\right) \\
X_{s, \min } \leq X_{s} \leq X_{s, \max } \quad s=1,2,3, \ldots, N_{s} \\
\mathrm{ds}_{\min } \leq \mathrm{ds} \leq \mathrm{ds}_{\max } \quad \mathrm{ds}=100,200,300, \ldots, 800 \\
h_{s} \geq h_{0} \quad s=1,2,3, \ldots, N_{s} .
\end{gathered}
$$




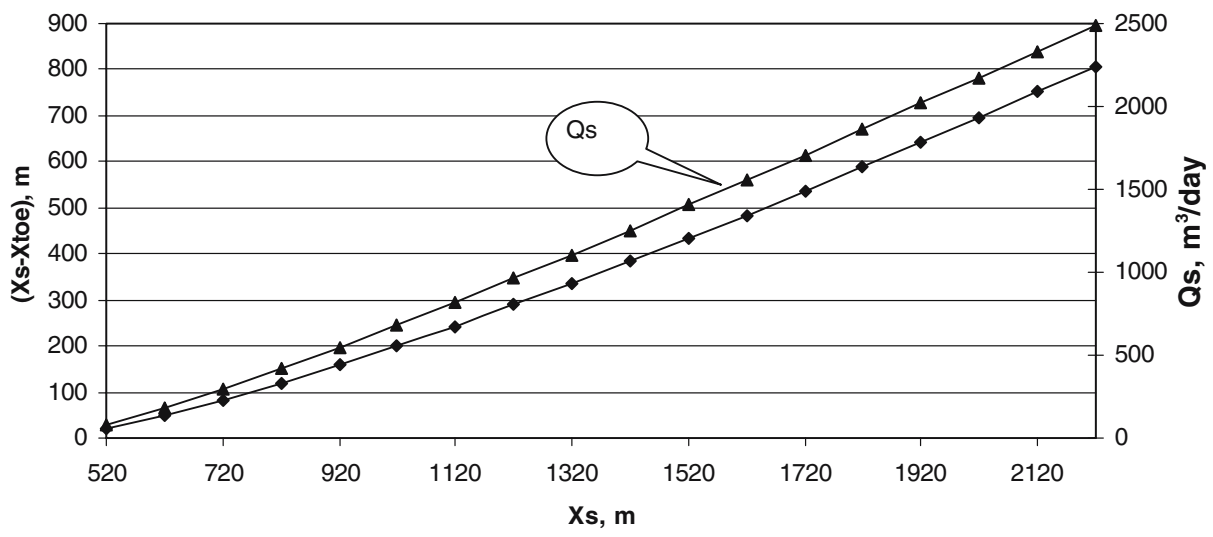

Figure 5 Maximum withdrawal $\left(Q_{s}\right)$, the distance between the toe of the interface and the control point before invasion $\left(X_{s}-X_{\text {toe }}\right)$ and the location $\left(X_{s}\right)$ for one well.

Formulating the problem in such a manner, and the cost of providing groundwater being less than other sources, the management model seeks to extract the maximum water from the aquifer maintaining the interface at the security distance (ds) set by decision makers.

\section{Applications}

In the following studies, the system represented in Figure 2 has been used with a general slope of $0.5 \%$ towards the ocean. The WTP (water treatment plant) and the PS (pumping station) have been positioned in the middle of aquifer some 3,500 m from the coast. Let us assume that the main supply line can be implemented in straight lines and it has a length of $1,000 \mathrm{~m}$ between PS and RDR (reservoir for distribution regulation). It is estimated that at the start of the undertaking, the average daily demand is $3,500 \mathrm{~m}^{3} /$ day with a rate of increase of $3 \%$ for the first phase and $1.87 \%$ for the second half of the 20 year life span (a linear growth has been considered). The average actual price of energy is $0.0848 € / \mathrm{kWh}$, admitting a growth following the equation for composite interest with a rate of $2 \%$. For economic analysis, the criterion of present value has been adopted with a $5 \%$ value for money. The aquifer has a thickness of $14 \mathrm{~m}$, hydraulic conductivity of $100 \mathrm{~m} /$ day and specific flow of $0.6 \mathrm{~m}^{3} / \mathrm{m}$ day. Without any groundwater extraction, the toe of the interface is located at $418 \mathrm{~m}$ from the ocean. As such allowing successive values for the security distance $(\mathrm{ds}=100 \mathrm{~m}, 200 \mathrm{~m}, \ldots)$, extraction locations should be implemented at distances $\left(X_{s}\right)$ not less than $520 \mathrm{~m}, 620 \mathrm{~m}, \ldots$, respectively.

Table I A three well system with the same $Q$

\begin{tabular}{llllll}
\hline & $X_{s, m}$ & $Y_{s, m}$ & $X_{\text {toe, } m}$ & $X_{s}-X_{\text {toe }}(\mathrm{m})$ & $Q_{s}\left(\mathrm{~m}^{3} / \mathrm{day}\right)$ \\
\hline Well 1 & 2,000 & 1,000 & 1,055 & 945 & 951 \\
Well 2 & 2,000 & 0 & 1,600 & 400 & 951 \\
Well 3 & 2,000 & $-1,000$ & 1,055 & 945 & 951 \\
Total & & & & 2,853 \\
\hline
\end{tabular}


Table II An alternative case with three wells and the same $Q$

\begin{tabular}{llllll}
\hline & $X_{s, m}$ & $Y_{s, m}$ & $X_{\text {toe, } m}$ & $X_{s}-X_{\text {toe }}(\mathrm{m})$ & $Q_{s}\left(\mathrm{~m}^{3} /\right.$ day $)$ \\
\hline Well 1 & 1,780 & 1,000 & 1,264 & 516 & 951 \\
Well 2 & 2,000 & 0 & 1,600 & 400 & 951 \\
Well 3 & 1,780 & $-1,000$ & 1,264 & 516 & 951 \\
Total & & & & 2,853 \\
\hline
\end{tabular}

Location of one Extraction Point In this case, it is intended to find the distance of a groundwater extraction point (location) from the ocean, allowing the maximum withdrawal while respecting the security distance. The costs were assumed to be the same in any part of the aquifer. Running the optimization/simulation model gave the location to be $X_{s, \max }$. For example assuming a maximum of $1,650 \mathrm{~m}$ from the sea $\left(420 \mathrm{~m} \leq X_{s} \leq 1,650 \mathrm{~m}\right)$, the solution of the model will be $1,650 \mathrm{~m}$ and a possible extraction of $1,600 \mathrm{~m}^{3} /$ day with a security distance of $500 \mathrm{~m}$. With land availability of $2,200 \mathrm{~m}$, the numbers are $2,460 \mathrm{~m}^{3} /$ day and $800 \mathrm{~m}$, respectively.

In a different setup, it is interesting to know for any eventual location, what are the optimum withdrawal and security distance. Using a grid of $10 \mathrm{~m}$ for $X$ and $100 \mathrm{~m}$ for ds, the results of the model are registered in Figure 3.

The decision maker should decide on the security distance which in turn can indicate the location and the corresponding maximum extraction. Figure 4 helps this decision, as it gives the non-linear behavior of the system.

One of the major decisions is about the distance between the toe of the interface and the control point (well) before it gets invaded by saltwater. This is particularly important, as there is non-linearity in the system (refer to Figure 1). Logically, for a particular location, the maximum extraction occurs immediately before the invasion. Figure 5 shows the maximum allowable extraction and the distance between the toe of the interface and the control point before invasion for each eventual location.

Location of a Number of Extraction Points To have an easier maintenance and operation, it is generally interesting to install equipments with the same characteristics such as having the same $Q$. So the problem is to know the location of the wells while maximizing the economic return and respecting the security distance (ds). The following extra restriction should be applied:

$$
Q_{s+1}=Q_{1} \quad s=1,2,3, \ldots,\left(N_{s}-1\right) .
$$

Table I shows the results of using three wells, a maximum distance of 2,000 $\mathrm{m}$ from the ocean, and pumps with a maximum extraction of $1,000 \mathrm{~m}^{3} /$ day.

The same situation, i.e., $400 \mathrm{~m}$ of security distance and $2,853 \mathrm{~m}^{3} /$ day can be achieved with two of the wells closer to the ocean as shown in Table II (though this alternative gives lower benefits).

Table III A three well system and optimized extractions

\begin{tabular}{llllll}
\hline & $X_{s, m}$ & $Y_{s, m}$ & $X_{\text {toe, } m}$ & $X_{s}-X_{\text {toe }}(\mathrm{m})$ & $Q_{s}\left(\mathrm{~m}^{3} / \mathrm{day}\right)$ \\
\hline Well 1 & 2,000 & 1,000 & 1,068 & 932 & 975 \\
Well 2 & 2,000 & 0 & 1,600 & 400 & 924 \\
Well 3 & 2,000 & $-1,000$ & 1,068 & 932 & 975 \\
Total & & & & 2,874 \\
\hline
\end{tabular}




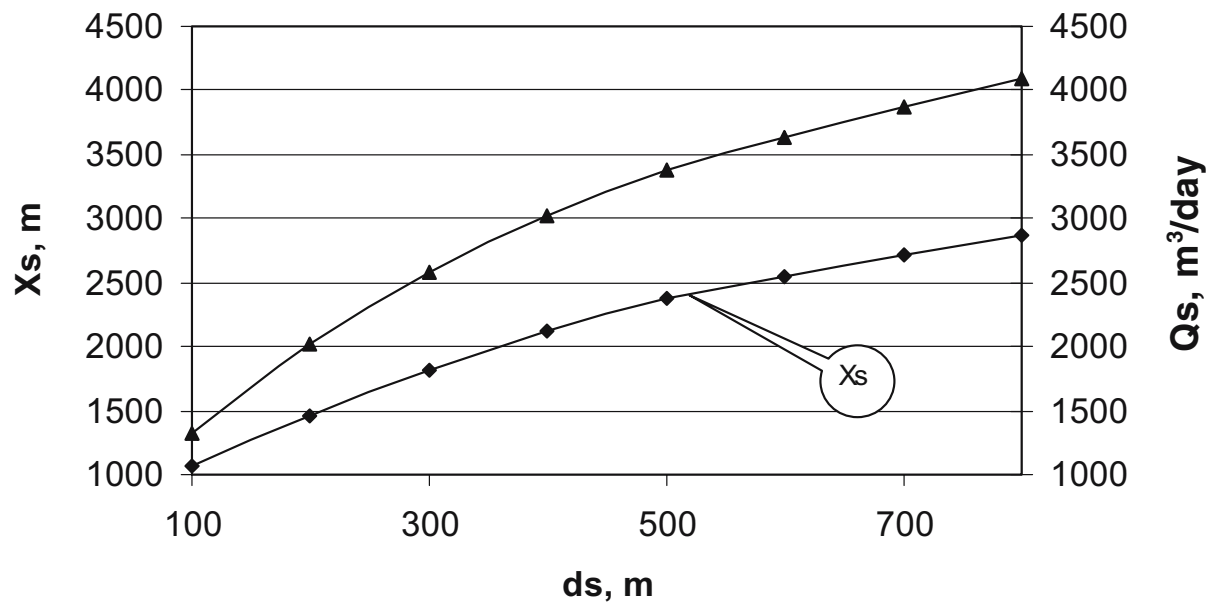

Figure 6 Security distance $(d s)$ vs. location $\left(X_{s}\right)$ vs. maximum withdrawal $\left(Q_{s}\right)$ for three wells.

However if the optimum withdrawal from each well is being sought (i.e., without the restriction given in Equation (11)), the model gives the results in Table III.

Figures $6,7,8,9,10,11,12$ and 13 show the results for 3,5 and 11 wells.

These figures give more interesting information about the phenomenon under study (besides the explanations given for Figures 3 and 5). For example due to non-linearity, the security can be reasonably increased by a small inward move of the location of the wells. Or that such movement causes the interface to jump further from the wells. Another example is that the comparative analyses of these figures shows the distance from the coastline that the location of the wells are of less interest in relation to seawater intrusion.

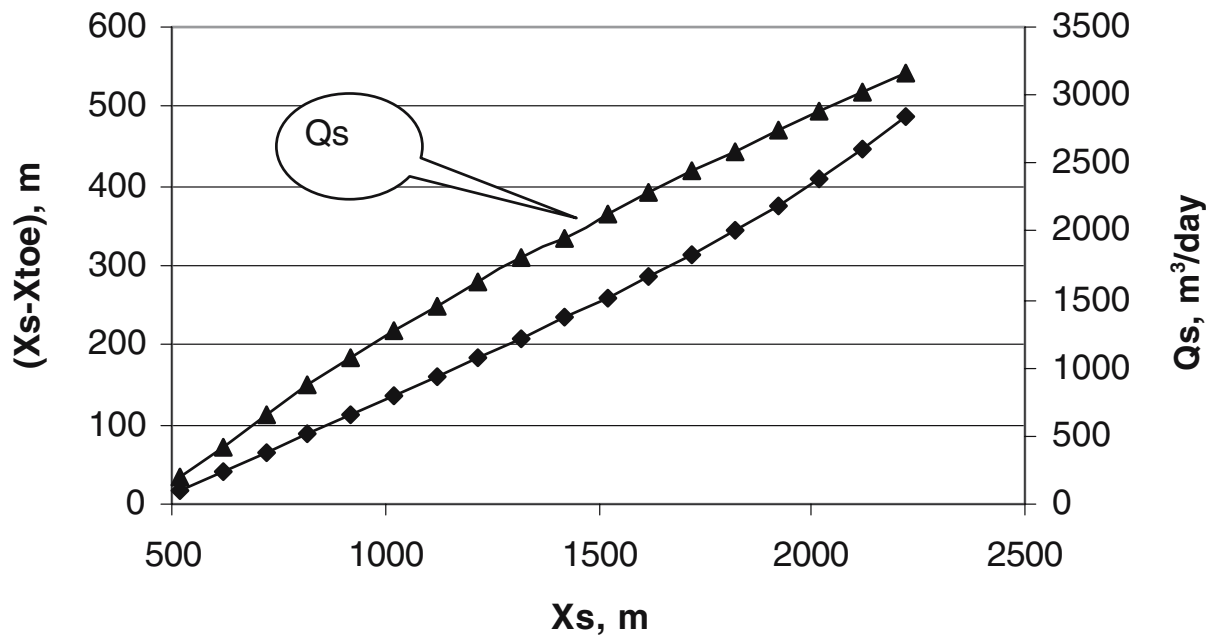

Figure 7 Maximum withdrawal $\left(Q_{s}\right)$, the distance between the toe of the interface and the control point before invasion $\left(X_{s}-X_{\text {toe }}\right)$ and the location $\left(X_{s}\right)$ for three wells. 


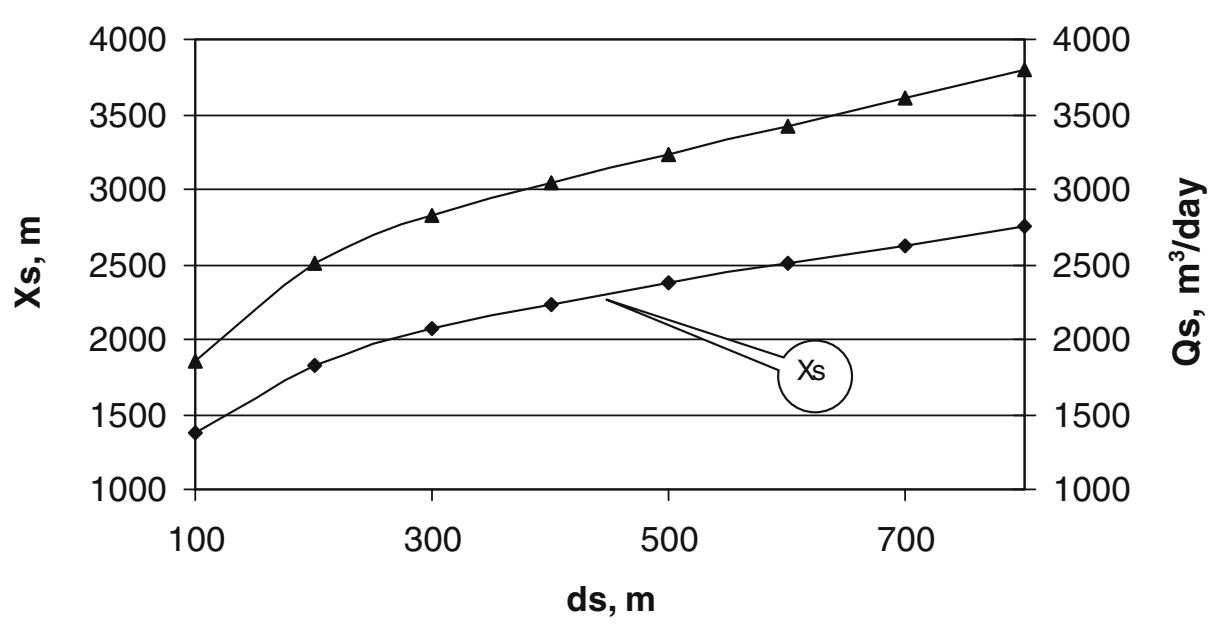

Figure 8 Security distance $(d s)$ vs. location $\left(X_{s}\right)$ vs. maximum withdrawal $\left(Q_{s}\right)$ for five wells.

Location of Artificial Recharge The inverse of the above process could be used to find the best location for artificial recharge of a coastal aquifer. Even a number of wells can be implemented in order to create a 'barrier' to saltwater intrusion. It is best formed by a set of wells more or less parallel to the coast. For example in Figure 2, a weir at the river can serve to make water available for artificial recharge and the creation of a barrier. This idea was applied to an aquifer in the southern part of Portugal called Mexilhoeira GrandePortimão. It is not the purpose of this paper to develop this case. It only suffices to mention that saltwater invaded the aquifer some 10 years ago and the municipal wells were abandoned because of over-exploitation. The model showed that there were possibilities of either using a couple of existing wells or constructing new ones in order to be used as recharge points and to make the system sustainable. Its rehabilitation is under study.

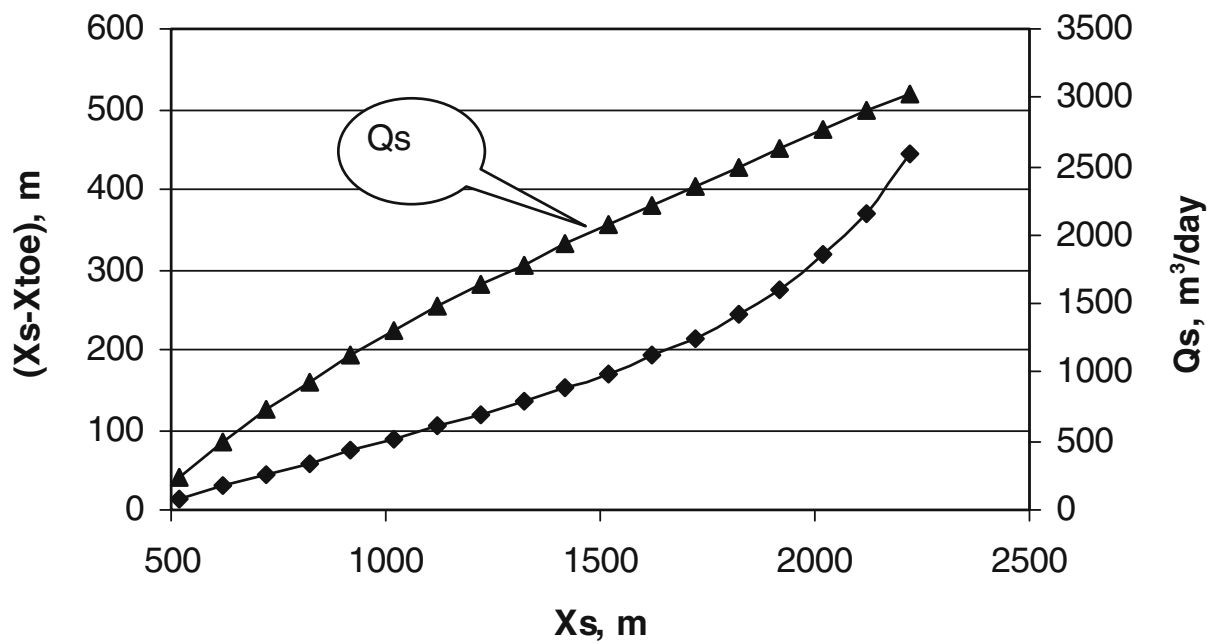

Figure 9 Maximum withdrawal $\left(Q_{s}\right)$, the distance between the toe of the interface and the control point before invasion $\left(X_{s}-X_{\text {toe }}\right)$ and the location $\left(X_{s}\right)$ for five wells. 


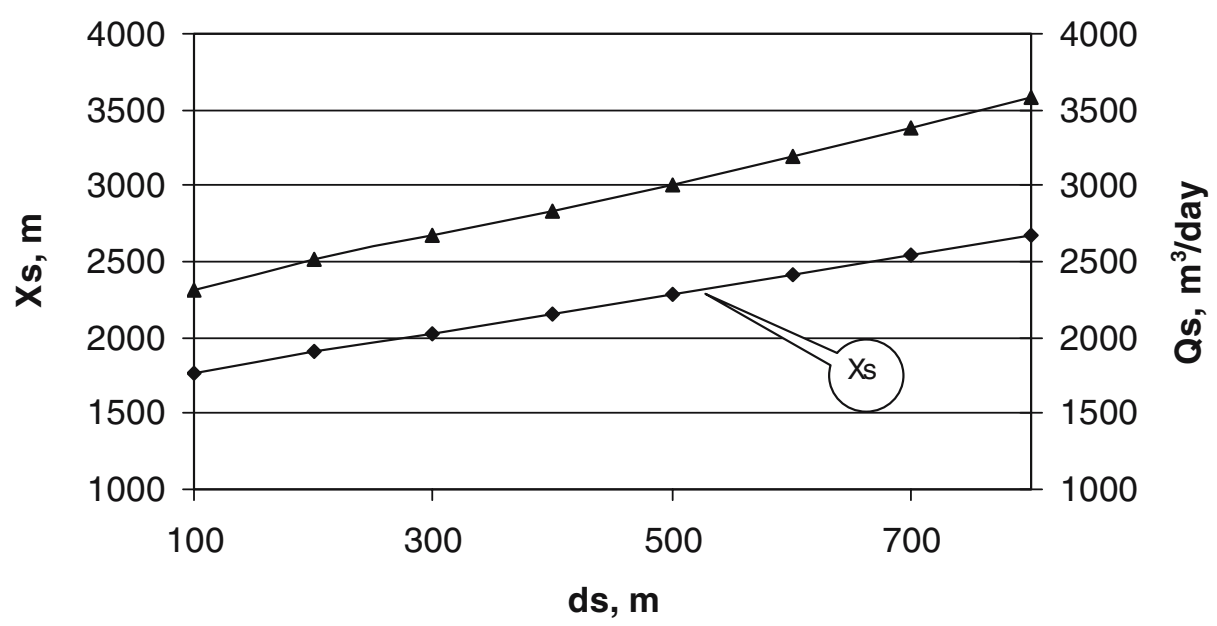

Figure 10 Security distance $(d s)$ vs. location $\left(X_{s}\right)$ vs. maximum withdrawal $\left(Q_{s}\right)$ for 11 wells.

\section{Conclusions}

An optimization/simulation model was developed and tested. The case studies showed that the model is capable of performing optimized planning and management of the locations of extraction (and recharge-not presented in this paper) points in a coastal aquifer. Most of the population of Portugal lives in coastal zones and use wells to capture the groundwater that flows to the ocean. It is important to develop sustainable strategies of groundwater extraction for our regional water supply systems.

This paper showed some results relating different domain variables and their non-linear behavior. Locations were analyzed as a function of groundwater withdrawal and security distance. The maximum allowable extraction and the distance between the toe of the interface and the control point before invasion were studied for each eventual location. It

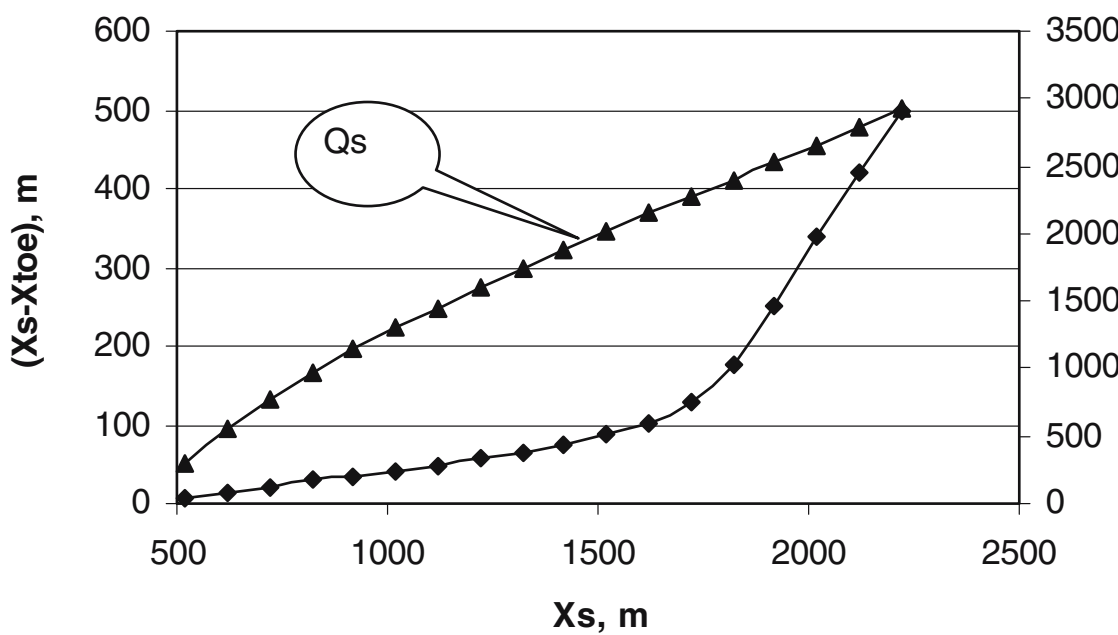

Figure 11 Maximum withdrawal $\left(Q_{s}\right)$, the distance between the toe of the interface and the control point before invasion $\left(X_{s}-X_{\text {toe }}\right)$ and the location $\left(X_{s}\right)$ for 11 wells. 


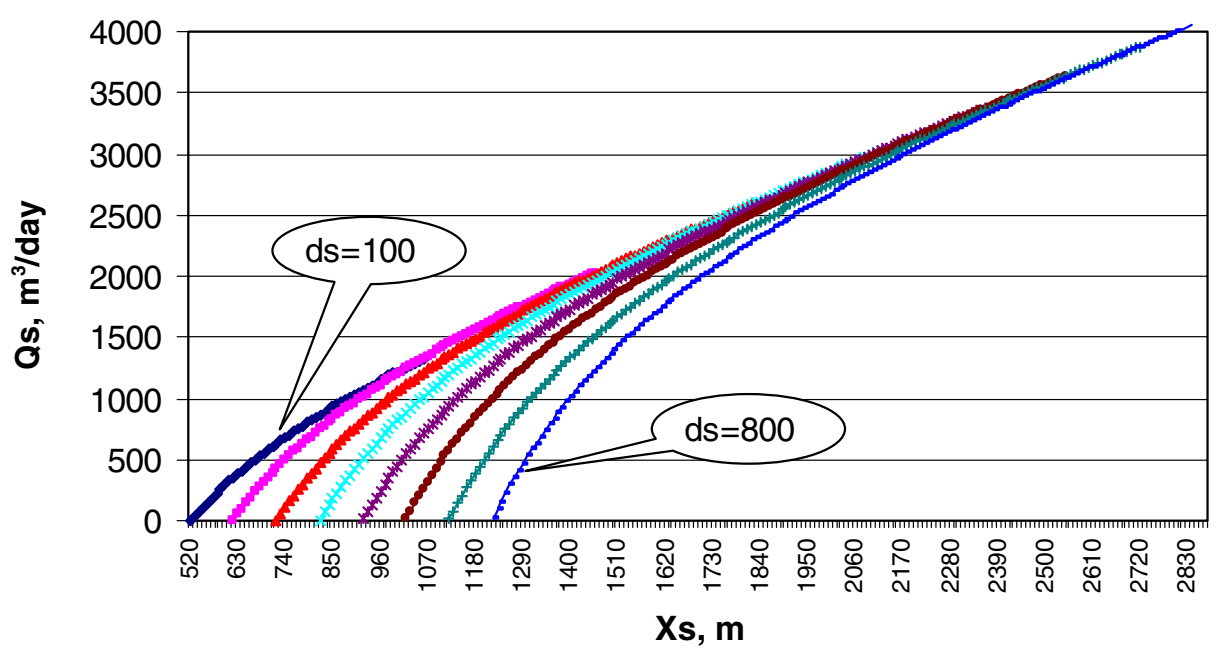

Figure 12 Extraction as a function of the security distance and location for three wells $(\mathrm{ds}=100,200, \ldots$, $800 \mathrm{~m})$.

was found that the security of water resources systems can be reasonably increased by a small inward move of the location of the wells. Proper artificial recharge and its locations are other aspects of the same issue. In all these situations, the non-linearity within the system has to be taken into account. Trying to extract the maximum quantity before experiencing saltwater intrusion is very risky as the saline interface goes through a sharp jump and invades the wells.

Among other future work, we are currently pursuing the inclusion of the system into a Geographic Information System, and defining protective perimeters for public water supply systems as promoted by the WFD (2000).

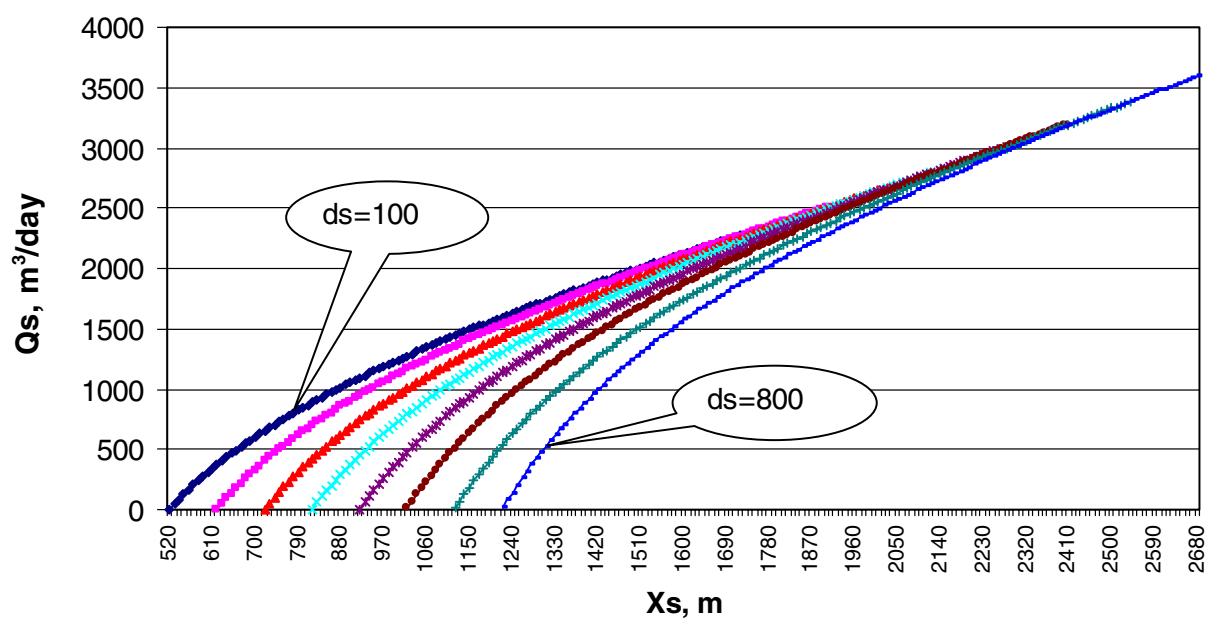

Figure 13 Extraction as a function of the security distance and location for 11 wells (ds $=100,200, \ldots$, $800 \mathrm{~m})$. 
Acknowledgments The authors wish to express thanks to the Science and Technology Foundation (FCT) for the financial support towards this project (POCTI/ECM/2512/9). Thanks are also due to the Portuguese National Laboratory of Civil Engineering (LNEC) and the Superior Technical Institute (IST) of the Technical University of Lisbon for their collaboration. We also would like to appreciate the support of the Civil Engineering Research Centre of the University of Minho.

\section{References}

Bakker M, Schars F (2002) The sea water intrusion (SWI) package manual, version 1, Dezembro

Benhachmi M, Ouazar D, Naji A, Cheng A, Harrouni K (2003) Pumpimg optimization in saltwater intruded aquifers by simple genetic algorithm - deterministic model. In: 2 nd international conference on saltwater intrusion and coastal aquifers - monitoring, modelling and management. Merida, Mexico

Emch Pamela G (1995) A nonlinear multiobjective management model for the conjunctive use of surface water and groundwater under conditions of potential saltwater intrusion. PhD dissertation, University of California, Los Angeles

Essaid HI (1990) The computer model SHARP, water-resources investigations report 90-4130. US Geological Survey, California

Ferreira da Silva JF (2003) Gestão optimizada à escala regional de sistemas aquíferos potencialmente sujeitos à intrusão salina - Um modelo global para o uso sustentável da água em regiões costeira. $\mathrm{PhD}$ dissertation, University of Minho (in Portuguese)

Ferreira da Silva JF, Haie N (2004) Evolutionary optimization for sustainable regional management of coastal groundwater (in preparation)

Finney BA, Willis R (1992) Quasi-three-dimensional optimization model of Jakarta basin. J Water Resour Plan Manage, ASCE 118(1):18-31

Goldberg DE (1989) Genetic algorithms is search, optimization and machine learning. Addison-Wesley, Reading, Massachusetts

Hallaji K, Yazicigil H (1996) Optimal management of a coastal aquifer in southern turkey. J Water Resour Plan Manage, ASCE 122(4):233-244

Nashikava T (1998) Water-resources optimization model for Santa Barbara, California. J Water Resour Plan Manage, ASCE 124(5):252-263

Rao SVN, Thandaveswara BS, Murty Bhallamudi S, Srinivasulu V (2003) Optimal groundwater management in deltaic regions using simulated annealing and neural networks. Water Resour Manag 17:409-428, Kluwer, Dordrecht, The Netherlands

Shamir U, Bear J, Gamliel A (1984) Optimal annual operation of a coastal aquifer. Water Resour Res 20 (4):435-444

Strack ODL (1989) Groundwater mechanics. Prentice-Hall, Englewood Cliffs, New Jersey

WFD (2000) Directive 2000/60/EC of the European parliament and of the council of 23 October 2000 establishing a framework for community action in the field of water policy. Official Journal of the European Communities 22.12.2000, L 327 pp 1-72 